\title{
Referral from vascular surgery to cardiovascular rehabilitation and related outcomes in patients with peripheral arterial disease: the THINKPAD-RELOADED survey
}

\author{
Marco Ambrosetti ${ }^{1}$, Pompilio Faggiano ${ }^{2}$, Cesare Greco ${ }^{3}$, Gian Francesco Mureddu ${ }^{3}$, Pier Luigi Temporelli ${ }^{4}$, \\ Roberto F.E. Pedretti ${ }^{1}$ On behalf of the THINKPAD-RELOADED study group \\ ${ }^{1}$ Department of Cardiac Rehabilitation, Istituti Clinici Scientifici Mangeri IRCCS, Pavia; ${ }^{2}$ Cardiology Division, Spedali \\ Civili and University of Brescia; ${ }^{3}$ Cardiology and Cardiac Rehabilitation Department, A.O. San Giovanni-Addolorata, \\ Rome; ${ }^{4}$ Department of Cardiac Rehabilitation, Istituti Clinici Scientifici Maugeri IRCCS, Veruno, Italy
}

\begin{abstract}
The utilization of cardiovascular rehabilitation (CR) programmes in patients with Lower Extremity Peripheral Artery Disease (LEPAD) is generally poor, with limited evidence of current policies for referral. The aim of the study was to evaluate, within a cohesive network of CR and vascular surgery facilities with facilitated referral process, the clinical characteristic of LEPAD patients referred to CR and related outcomes, as compared to patients not referred. The present is an observational prospective study of consecutive patients recruited at vascular surgery facilities. Out of 329 patients observed, the average
\end{abstract}

Correspondence: Marco Ambrosetti, Department of Cardiac Rehabilitation, Istituti Clinici Scientifici Maugeri IRCCS, Via S. Maugeri 4, 27100 Pavia, Italy.

Tel. +39.0382 .592613 .

E-mail: marco.ambrosetti@icsmaugeri.it

THINKPAD-RELOADED Study Group: Valentina Cremona, Martina Passera (Cunardo, Italy); Matteo Tozzi, Giuseppe Angrisano, Gabriele Piffaretti (Varese, Italy); Salvatore Pio Riccobono, Cristina Giannattasio, Andrea Ferrari, Alfredo Lista, Federico Romani (Milano Italy); Lorenza Dal Corso, Giuseppe Favretto (Motta di Livenza, Italy); Laura Nicolai, Edoardo Galeazzi (Treviso, Italy); Bruno Passaretti, Maria Orlando, Maria Elena Barzaghi, Marco Setti (Bergamo, Italy); Michela Palvarini, Anna Frisinghelli (Passirana di Rho, Italy); Gianmauro Mazzucco (Piossasco, Italy); Stefano Massucco (Turin, Italy); Alberto Ferrari Bardile, Teresa Aloi (Montescano, Italy); Mario Salerno (Tradate, Italy); Stefano Bonardelli (Brescia, Italy); Augusto Farina (Crema, Italy); Oreste Febo (Rivolta d'Adda, Italy).

Key words: peripheral arterial disease; rehabilitation; exercise; referral.

Received for publication: 27 May 2019.

Accepted for publication: 14 August 2019.

${ }^{\circ}$ Copyright: the Author(s), 2019

Licensee PAGEPress, Italy

Monaldi Archives for Chest Disease 2019; 89:1101

doi: 10.4081/monaldi.2019.1101

This article is distributed under the terms of the Creative Commons Attribution Noncommercial License (by-nc 4.0) which permits any noncommercial use, distribution, and reproduction in any medium, provided the original author(s) and source are credited. referral rate to CR was $34 \%$ (28\% and $39 \%$ in patients with and without recent peripheral revascularization, $\mathrm{p}<0.05)$. LEPAD patients entering the CR programme were similar to those who did not according to sex, age, the vascular surgery setting of evaluation, and localization of arterial lesions. Patients with moderate intermittent claudication and patients with acute limb ischemia as index event were more represented among those who attended CR (41\% vs $21 \%$ and $9 \%$ vs $2 \%$ respectively, $\mathrm{p}<0.05)$. Patients referred to CR had five times more episodes of acute coronary syndrome and heart failure as complication of the index event. The cardiovascular risk profile (obesity $29.5 \% \mathrm{vs}$ $11 \%, \mathrm{p}<0.05$; hypercholesterolemia $80 \%$ vs $61 \%, \mathrm{p}<0.05)$ was much worse in LEPAD patients referred to CR, but conversely, they better achieved secondary prevention targets, particularly for blood pressure control (97\% vs 57\%, p<0.05). All-cause 2year mortality in the whole patients' population was $6 \%$. Patients entering the CR programme displayed less events $(13.5 \%$ vs $37.7 \%, \mathrm{p}<0.05)$, mainly death $(3.1 \%$ vs $11.3 \%, \mathrm{p}<0.05)$ and limb-related events $(4.2 \%$ vs $15.2 \%, \mathrm{p}<0.05)$. The results of our study suggest that when a cohesive network of vascular surgery and CR facilities becomes available, the referral rate to rehabilitation may increase up to one third of eligible patients. Patients with higher comorbidity and cardiovascular risk seem to have priority in the referral process, nevertheless those with peripheral revascularization are still underestimated. Entering CR may ensure better cardiovascular risk profile and cardiovascular prognosis in LEPAD patients, and consequently the systematic adoption of this care model needs to be strongly recommended and facilitated.

\section{Introduction}

Cardiovascular Rehabilitation (CR) has been established as the most clinically and cost-effective intervention in cardiovascular disease (CVD) management [1], and patients with Lower Extremity Peripheral Artery Disease (LEPAD) have been formally identified as target groups for structured CR programmes, whose core components and intervention goals are now well recognized [2]. The most typical and disabling symptom in LEPAD is intermittent claudication (IC), being supervised exercise training (SET) included among strategies to increase walking distances since the beginning of the Nineties [3]. Nowadays, SET for IC displays high efficacy and safety [4] and is recommended 
as a first-line therapy [5,6]. Although this is called 'typical claudication', most patients with peripheral artery disease do not have these symptoms and often present with atypical painful legs, especially in the elderly, which may also require a rehabilitative approach due to the even greater mobility decline as compared to patients with IC [7]. Moreover, there is now convincing evidence that LEPAD patients following acute limb events or revascularization procedures - both surgical or percutaneous - could also be considered as target groups for rehabilitation [8], since a combination of surgical intervention and SET offered superior outcomes to monotherapy across multiple studies, particularly in terms of functional benefit $[9,10]$.

Even though the whole pattern of presentation of LEPAD could appropriately be now referred to $\mathrm{CR}$ - with shared expected outcomes, namely i) clinical stabilization and reduction of disability; ii) better cardiovascular prognosis and mortality; and iii) education and psychosocial support - this condition is still characterized by poor referral rates, due to several barriers at patient's and system's level. Reasons for nonparticipation may include low strength of endorsement from physicians, comorbid conditions, lack of social support, and other clinical and logistical factors [11]. However, the underuse of CR in LEPAD could also be explained by the limited availability of qualified programmes and subsequent recruitment competition; the latter phenomenon, indeed, may be particularly noticeable in the context of "general" CR, where the imbalance between supply and demand for usual cardiac conditions (such as acute coronary syndromes, cardiac surgery, or heart failure) inevitably gives LEPAD a lower priority.

To provide direction for potential solutions to improve the uptake of CR in LEPAD patients, it could be useful to explore the "physiological need" of CR interventions coming from the vascular surgery setting, in view of interorganizational collaboration and facilitated referral process. For this reason, the THINKPADRELOADED ("ATHerosclerosis of the lower extremIties as a liNKed comorbidity in Patients Admitted for carDiac rehabilitation - REassessment of gLobal Outcome According to DElivereD intervention") survey was carried out by the Italian Association of Cardiovascular Prevention and Rehabilitation (IACPR), with the aim to evaluate characteristics of LEPAD patients referred by vascular surgery units to CR facilities, as far as the impact of the referral process on cardiovascular prognosis.

\section{Patients and Methods}

In 2015, the IACPR carried out an educational project (i.e. the THINKPAD "ATHerosclerosis of the lower extremIties as a liNKed comorbidity in Patients Admitted for carDiac rehabilitation" project), aimed at increasing the awareness of the cardiac rehabilitation community about LEPAD, also supported by national multicentre observational studies [12]. As a second step, the IACPR organized an operational network by coupling five CR units with five another neighbouring vascular surgery facilities, on a voluntary basis, and facilitated local relationships and policies in order to take LEPAD into account as a qualified condition for rehabilitation within this closed network. Current guidelines on CR [1,2] were presented and discussed during ad hoc meetings. In a subsequent study period of 6 months, CR units were invited to give LEPAD the same consideration for referral as for other cardiac conditions, while vascular surgery facilities were invited to establish a local decision policy for patients potentially attending rehabilitation, based on clinical priorities.
The structured network was located in the Lombardy and Veneto regions of Italy, where LEPAD is considered by the Regional Health System as an appropriate and refundable condition both for residential and ambulatory CR [13]. The three primary endpoints of this THINKPAD-RELOADED prospective observational study were i) to analyse clinical characteristics and cardiovascular risk profile of patients referred ("CR group") and not referred ["usual care (UC) group"] by vascular surgery facilities to $\mathrm{CR}$ units; ii) to compare cardioprotective drugs and the achievement of secondary prevention targets between patients referred and not referred; and iii) to provide a 2-year follow-up for death from any cause, major adverse cardiovascular events and major adverse limb events in both groups.

The selection criteria, as for previous IACPR collaborative research initiatives, were based on the centre's recruitment potential and (for CR facilities) experience in administering the core components of the centre's rehabilitation program that had to be in concordance with $\mathrm{CR}$ international guidelines [1,2]. The study complied with the Italian Medicines Agency (AIFA) Registry of Observational Studies requirements and the study protocol was approved by the Ethical Committee of each participating unit.

All consecutive patients discharged alive or observed during a routine ambulatory visit at the vascular surgery facility within the study period were considered. Criteria for patients' inclusion were a documented diagnosis of LEPAD as a primary indication for hospitalization or ambulatory consultation. Patients with life expectancy lower than six months or missing consent were excluded. Sociodemographic information about each patient plus data on comorbidities, global risk profile, clinical status, lifestyle, and risk factor management were collected. THINKPAD-RELOADED did not involve any experimentation of drugs or any diagnostic tests, care interventions or pharmacological treatments that were not part of the clinical practice routinely adopted by each participating unit. Patients not completing the CR programme were excluded from analysis.

The conducted CR was the usual standardised, intensive, multimodal rehabilitation programme in Italy with a mean duration of three weeks, which usually begins within 14 days after discharge from hospital. This CR programme included patient assessment, exercise training, diet/nutritional counselling, smoking cessation, cardiovascular risk factor (lipid and blood pressure) management, and psychosocial intervention as major core components defined by current guidelines [1], on an intention-totreat basis. Cardioprotective drugs considered were reninangiotensin system modulators, beta-blockers, statins, ezetimibe, antiplatelet agents, and anticoagulants. Secondary prevention targets (namely, systolic blood pressure $\leq 140 \mathrm{mmHg}$, diastolic blood pressure $\leq 90 \mathrm{mmHg}$, LDL-Cholesterol $\leq 100 \mathrm{mg} / \mathrm{dl}$, and uric acid $\leq 6 \mathrm{mg} / \mathrm{dl}$ ) were evaluated at the end of the CR programme and at vascular surgery evaluation in patients referred and not referred to $\mathrm{CR}$ respectively. The following events were considered during follow-up: acute coronary syndrome (ACS), coronary revascularization (Crev), stroke, acute limb ischemia (ALI), chronic limb ischemia (CLI), peripheral lower limb revascularization (PRev), and amputation.

\section{Sample size calculation}

To estimate the minimum number of patients to produce representative survey result we hypothesized that, within a cohesive net- 
work potentially providing fast and direct track from vascular surgery to CR facilities, LEPAD would be as likely to be referred as other cardiac diseases. We determined that to achieve the $95 \%$ confidence interval around the estimate of $35 \%$ of average utilization of CR for major qualifying cardiac diagnoses [14,15] with a $7 \%$ absolute precision, a minimum of 178 subjects should have been targeted.

\section{Statistical analysis}

All data were inspected, downloaded and securely stored by the IACPR Study Center for Research and Education. Results were shown as mean (SD) or as proportions, and comparisons were by $t$-test (for interval data with normal distribution), $\chi^{2}$ test (for nominal data) or Mann-Witney test (for interval data with skewed distribution) as appropriate. The SPSS package (SPSS Inc., SPSS Statistics for Windows, ver. 17.0., release 2008) was used to perform statistical analysis. Statistical significance was set at $\mathrm{p}<0.05$ (two-tailed)

\section{Results}

The survey included 329 consecutive patients, 112 (34\%) of whom were referred from vascular surgery facilities to a CR programme, with a time to entry of $7 \pm 2$ days of treatment. The referral rate was $28 \%$ and $39 \%(\mathrm{p}<0.05)$ in patients with and without peripheral revascularization. LEPAD patients entering the CR programme (Table 1) were similar to those who did not according to sex, age, the vascular surgery setting of evaluation, and localization of arterial lesions. Concerning LEPAD presentation, patients with moderate IC (i.e. grade I, categories 2 according to Rutherford classification) and patients with ALI as index event were more represented among those who attended CR, and accounted for half of the whole referred population. Patients without any revascularization at index event accounted for $62.5 \%$ of the whole CR group, as compared to $48.5 \%$ of those who were not referred to rehabilitation $(\mathrm{p}<0.05)$, and particularly endovascular procedures were less frequently observed in LEPAD patients referred to CR $(10.7 \%$ vs $19.4 \%, \mathrm{p}<0.05)$. LEPAD patients with peripheral revascularization and referred to CR suffered more often from cardiac complications during the acute phase, with a prevalence of ACS and transient heart failure (HF) five times higher than those not entering the rehabilitation programme. Conditions such as chronic obstructive pulmonary disease (COPD) ( $29 \%$ vs $15 \%, \mathrm{p}<0.05)$, carotid stenosis $(42 \%$ vs $30 \%, \mathrm{p}<0.05)$, and past coronary revascularization $(45 \%$ vs $33 \%, \mathrm{p}<0.05)$ were also more represented in the LEPAD group attending CR. Concerning cardiovascular risk profile, the prevalence of obesity $(29.5 \%$ vs $11 \%, \mathrm{p}<0.05)$ and hypercholesterolemia $(80 \%$ vs $61 \%, \mathrm{p}<0.05)$ were significantly higher in LEPAD patients referred to CR, while an unhealthy lifestyle - in terms of current smoking (33\% vs $21 \%$, $\mathrm{p}<0.05)$, low intake of fruit/vegetables $\left(24 \% v_{s} 8 \%, \mathrm{p}<0.05\right)$, and low fish intake $(36 \%$ vs $21 \%, \mathrm{p}<0.05)$ - was more frequently observed among patients not referred to CR units.

All patients completed of the CR program, with a duration of $20 \pm 7$ days. Among diagnostic tests, ankle-brachial index was performed in $35(31 \%)$ patients during rehabilitation, as compared to $63 \%$ of cases during observation at the vascular surgery facility $(p<0.05)$. All patients entering the CR programme received struc- tured physical training, whose prescription was guided by treadmill test in $93 \%$ of cases, with improvement of both pain free (from $159 \pm 125$ to $464 \pm 381$ meters, $\mathrm{p}<0.05$ ) and maximal (from $292 \pm 223$ to $779 \pm 648$ meters, $p<0.05$ ) walking distances, as evaluated by means of treadmill test. Among other core components of CR intervention, diet/nutritional counselling, smoking cessation, cardiovascular risk factor (lipid and blood pressure) management, and psychosocial interventions were effectively delivered in $92 \%$, $67 \%, 100 \%$, and $86 \%$ of cases respectively.

As compared to patients solely treated at the vascular surgery facility, those completing the CR programme (Table 2) were taking more renin-angiotensin system modulators and lipid-lowering agents; they were also prescribed less heparin, while the utilization of beta-blockers and antiplatelet agents was similar in both groups.

The utilization of other pharmacological approaches to increase walking distance in the UC and the CR group was as follows: cilostazol $12 \%$ and $11 \%$ ( $\mathrm{p}=\mathrm{NS}$ ), pentoxifylline $4 \%$ and $3 \%$ $(\mathrm{p}=\mathrm{NS})$, and mesoglycan $1 \%$ and $5 \%$ respectively $(\mathrm{P}<0.05)$.

The proportion of patients who achieved secondary prevention targets for blood pressure was significantly higher among the CR group as compared to the UC group ( $97 \%$ vs $57 \%, \mathrm{p}<0.05)$, while lipid control was similar (Figure 1). Levels of LDL-cholesterol were $100 \pm 41 \mathrm{mg} / \mathrm{dl}$ and $83 \pm 33 \mathrm{mg} / \mathrm{dl}$ in the UC e CR group respectively ( $\mathrm{p}=\mathrm{NS}$ ). When lipid targets were modulated according to the presence of previous ACS (i.e. LDL-C $\leq 70 \mathrm{mg} / \mathrm{dl}$ instead of $\leq 100$ $\mathrm{mg} / \mathrm{dl}$ ) [16], patients referred to CR displayed higher achievement of therapeutic goals $(64 \%$ vs $48 \%, \mathrm{p}<0.05)$. The therapeutic target for uric acid was also more warranted in the CR group (71\% vs $26 \%, \mathrm{p}<0.05)$.

A total of 33 patients ( $22 \%$ of 149 evaluated) experienced one or more recurrent $\mathrm{CV}$ events during the 2-year follow-up, $61 \%$ of whom were in the UC group (Figure 2). All-cause mortality in the whole patients' population was $6 \%$. Patients entering the CR programme displayed less events ( $13.5 \%$ vs $37.7 \%, \mathrm{p}<0.05)$, mainly death $(3.1 \%$ vs $11.3 \%, \mathrm{p}<0.05)$ and limb-related events $(4.2 \%$ vs $15.2 \%, \mathrm{p}<0.05)$, while the prevalence of coronary events was similar among the two groups.

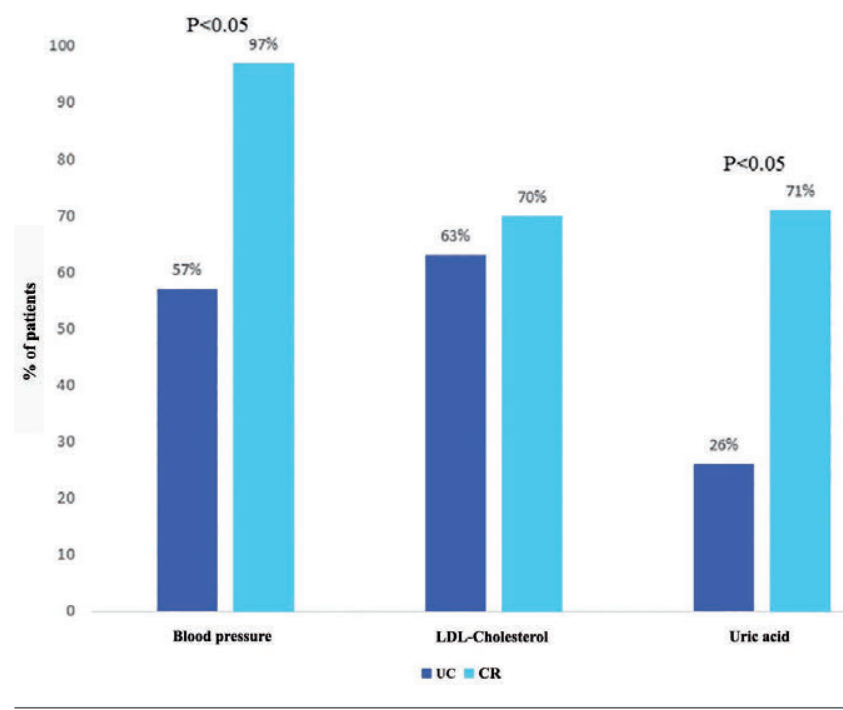

Figure 1. Therapeutic targets in LEPAD patients not referred to (UC) and at the end (CR) of cardiovascular rehabilitation. UC, usual care; $C R$, cardiovascular rehabilitation. 
Table 1. Characteristics of LEPAD patients observed in the vascular surgery network, according to no-referral (UC) and referral (CR) to cardiovascular rehabilitation programmes.

\begin{tabular}{|c|c|c|c|c|c|c|}
\hline & & $\begin{array}{c}\text { UC pts } \\
(n=217) \\
n\end{array}$ & $\%$ & $\begin{array}{c}\text { CR pts } \\
(n=112) \\
n\end{array}$ & $\%$ & p \\
\hline Demographics & $\begin{array}{l}\text { Males } \\
\text { Females } \\
\text { Age (yrs) }\end{array}$ & $\begin{array}{c}169 \\
48 \\
71 \pm 9\end{array}$ & $\begin{array}{l}77.9 \\
22.1\end{array}$ & $\begin{array}{c}88 \\
24 \\
72 \pm 8\end{array}$ & $\begin{array}{l}78.6 \\
21.4\end{array}$ & $\begin{array}{l}\text { NS } \\
\text { NS } \\
\text { NS }\end{array}$ \\
\hline Setting & $\begin{array}{l}\text { In-hospital } \\
\text { Out-of-hospital }\end{array}$ & $\begin{array}{l}102 \\
115 \\
\end{array}$ & $\begin{array}{l}47.0 \\
53.0\end{array}$ & $\begin{array}{l}40 \\
72 \\
\end{array}$ & $\begin{array}{l}35.7 \\
64.3\end{array}$ & $\begin{array}{l}\mathrm{NS} \\
\mathrm{NS}\end{array}$ \\
\hline PAD classification & $\begin{array}{l}\text { Fontaine 1/ Rutherford grade } 0 \text {, cat.0 } \\
\text { Fontaine 2A/ Rutherford grade I, cat. } 1 \\
\text { Fontaine 2B/ Rutherford grade I, cat. } 2 \\
\text { Fontaine 2B/ Rutherford grade I, cat. } 3 \\
\text { Fontaine 3/ Rutherford grade II, cat. } 4 \\
\text { Fontaine 4/ Rutherford grade III, cat. } 5 \\
\text { Fontaine 4/ Rutherford grade III, cat. } 6 \\
\text { ALI }\end{array}$ & $\begin{array}{c}19 \\
48 \\
45 \\
55 \\
20 \\
19 \\
6 \\
5\end{array}$ & $\begin{array}{c}8.8 \\
22.1 \\
20.7 \\
25.3 \\
9.2 \\
8.8 \\
2.8 \\
2.3\end{array}$ & $\begin{array}{c}1 \\
29 \\
46 \\
9 \\
5 \\
8 \\
4 \\
10\end{array}$ & $\begin{array}{c}0.9 \\
25.9 \\
41.1 \\
8.0 \\
4.5 \\
7.1 \\
3.6 \\
8.9\end{array}$ & $\begin{array}{l}<0.05 \\
\text { NS } \\
<0.05 \\
<0.05 \\
\text { NS } \\
\text { NS } \\
\text { NS } \\
<0.05\end{array}$ \\
\hline Localization of arterial lesions & $\begin{array}{l}\text { Aortoiliac } \\
\text { Femoropopliteal/infrapopliteal } \\
\text { Both } \\
\text { Not available }\end{array}$ & $\begin{array}{c}39 \\
132 \\
43 \\
3\end{array}$ & $\begin{array}{c}18.0 \\
60.8 \\
19.8 \\
1.4\end{array}$ & $\begin{array}{c}13 \\
69 \\
29 \\
1\end{array}$ & $\begin{array}{c}11.6 \\
61.6 \\
25.9 \\
0.9\end{array}$ & $\begin{array}{l}\text { NS } \\
\text { NS } \\
\text { NS } \\
\text { NS }\end{array}$ \\
\hline Revascularization procedure at enrolment & $\begin{array}{l}\text { None } \\
\text { Surgery } \\
\text { Endovascular } \\
\text { Combined surgery and endovascular } \\
\text { Other }\end{array}$ & $\begin{array}{l}108 \\
45 \\
42 \\
12 \\
10\end{array}$ & $\begin{array}{c}49.8 \\
20.7 \\
19.4 \\
5.5 \\
4.6\end{array}$ & $\begin{array}{l}70 \\
18 \\
12 \\
6 \\
6\end{array}$ & $\begin{array}{l}62.5 \\
16.1 \\
10.7 \\
5.4 \\
5.4\end{array}$ & $\begin{array}{l}<0.05 \\
\text { NS } \\
<0.05 \\
\text { NS } \\
\text { NS }\end{array}$ \\
\hline Complications among revascularized patients at enrolment & $\begin{array}{l}\text { ACS } \\
\text { Heart failure } \\
\text { Arrhythmias } \\
\text { ALI/CLI } \\
\text { Major bleeding } \\
\text { Infections }\end{array}$ & $\begin{array}{c}2 \\
2 \\
1 \\
2 \\
11 \\
1 \\
\end{array}$ & $\begin{array}{c}1.8 \\
1.8 \\
0.9 \\
1.8 \\
10.1 \\
0.9\end{array}$ & $\begin{array}{l}5 \\
5 \\
2 \\
3 \\
8 \\
5\end{array}$ & $\begin{array}{c}11.9 \\
11.9 \\
4.8 \\
7.1 \\
19.0 \\
11.9\end{array}$ & $\begin{array}{l}<0.05 \\
<0.05 \\
\text { NS } \\
\text { NS } \\
\text { NS } \\
<0.05\end{array}$ \\
\hline & Acute kidney failure & 4 & 3.7 & 2 & 4.8 & NS \\
\hline Comorbidities & $\begin{array}{l}\text { Previous ACS } \\
\text { Previous coronary revascularization } \\
\text { Chronic heart failure } \\
\text { Paroxysmal or chronic AF } \\
\text { Previous ALI/CLI } \\
\text { Previous lower limbs revascularization } \\
\text { Previous carotid revascularization } \\
\text { Previous treatment of AAA } \\
\text { Previous TIA/stroke } \\
\text { Actual carotid stenosis }>50 \% \\
\text { Previous VTE } \\
\text { Actual renal artery stenosis } \\
\text { Previous limb amputation } \\
\text { COPD } \\
\text { Chronic kidney disease }\end{array}$ & $\begin{array}{l}75 \\
72 \\
14 \\
14 \\
30 \\
62 \\
23 \\
14 \\
18 \\
65 \\
6 \\
2 \\
8 \\
33 \\
32\end{array}$ & $\begin{array}{c}34.6 \\
33.2 \\
6.5 \\
6.5 \\
13.8 \\
28.6 \\
10.6 \\
6.5 \\
8.3 \\
30.0 \\
2.8 \\
0.9 \\
3.7 \\
15.2 \\
14.7\end{array}$ & $\begin{array}{c}39 \\
50 \\
12 \\
12 \\
14 \\
27 \\
17 \\
5 \\
9 \\
47 \\
2 \\
3 \\
3 \\
32 \\
18\end{array}$ & $\begin{array}{c}34.8 \\
44.6 \\
10.7 \\
10.7 \\
12.5 \\
24.1 \\
15.2 \\
4.5 \\
8.0 \\
42.0 \\
1.8 \\
2.7 \\
2.7 \\
28.6 \\
16.1\end{array}$ & $\begin{array}{l}\text { NS } \\
<0.05 \\
\text { NS } \\
\text { NS } \\
\text { NS } \\
\text { NS } \\
\text { NS } \\
\text { NS } \\
\text { NS } \\
<0.05 \\
\text { NS } \\
\text { NS } \\
\text { NS } \\
<0.05 \\
\text { NS }\end{array}$ \\
\hline Cardiovascular risk factors / lifestyle & $\begin{array}{l}\text { Obesity } \\
\text { Hypertension } \\
\text { Diabetes } \\
\text { Hypercholesterolemia } \\
\text { Hypertriglyceridemia } \\
\text { Hyperuricemia } \\
\text { Family history of CV disease } \\
\text { Current smoking } \\
\text { Past smoking } \\
\text { Low physical activity } \\
\text { Low intake of fruit/vegetables } \\
\text { Low fish intake }\end{array}$ & $\begin{array}{c}23 \\
180 \\
81 \\
132 \\
20 \\
18 \\
11 \\
72 \\
74 \\
92 \\
53 \\
78\end{array}$ & $\begin{array}{c}10.6 \\
82.9 \\
37.3 \\
60.8 \\
9.2 \\
8.3 \\
5.1 \\
33.2 \\
34.1 \\
42.4 \\
24.4 \\
35.9\end{array}$ & $\begin{array}{c}33 \\
89 \\
47 \\
90 \\
9 \\
9 \\
39 \\
24 \\
48 \\
54 \\
9 \\
24\end{array}$ & $\begin{array}{c}29.5 \\
79.5 \\
42.0 \\
80.4 \\
8.0 \\
8.0 \\
34.8 \\
21.4 \\
42.9 \\
48.2 \\
8.0 \\
21.4\end{array}$ & $\begin{array}{l}<0.05 \\
\text { NS } \\
\text { NS } \\
<0.05 \\
\text { NS } \\
\text { NS } \\
<0.05 \\
<0.05 \\
\text { NS } \\
\text { NS } \\
<0.05 \\
<0.05\end{array}$ \\
\hline
\end{tabular}

UC, usual care; CR, cardiovascular rehabilitation; PAD, peripheral arterial disease; ALI, acute limb ischemia; ACS, acute coronary syndrome; CLI, chronic limb ischemia; AF, atrial fibrillation; AAA, abdominal aortic aneurysm; TIA, transient ischemic attack; VTE, venous thromboembolism; COPD, chronic obstructive pulmonary disease; CV, cardiovascular. 


\section{Discussion}

In the present observational study, patients referred from vascular surgery to CR facilities (namely, about one third of all observed) displayed more comorbidities and cardiometabolic risk factors, were less revascularized, and presented more coronary complications after the index event as compared to those who were not. Apart from functional benefit, the CR programme also resulted in a significant enhancement of the use of cardioprotective drugs and of cardiovascular risk profile, especially in terms of blood pressure control. Two years after CR, referred patients reduced 2-year mortality by three times and limb-related (i.e. a combined end point of ALI, CLI, and PRev) events almost by twice, while coronary (i.e. ACS and coronary revascularization) events were not significantly modified.

To date, few evidence exist about current utilization of CR

Table 2. Drug therapies in LEPAD patients not referred to (UC) and at the end (CR) of cardiovascular rehabilitation.

\begin{tabular}{lccccc} 
& $\begin{array}{c}\text { UC } \\
(n=217) \\
n\end{array}$ & $\%$ & $\begin{array}{c}\text { CR } \\
(n=112)\end{array}$ & $\%$ & p \\
ACE-I/ARB & 139 & 64.1 & 99 & 88.0 & $<0.05$ \\
BB & 100 & 46.2 & 52 & 46.7 & NS \\
\hline Statin & 124 & 57.2 & 99 & 88.0 & $<0.05$ \\
Ezetimibe & 7 & 3.4 & 18 & 16.0 & $<0.05$ \\
\hline Antiplatelet agents & 190 & 87.6 & 102 & 90.7 & NS \\
Heparin & 18 & 8.3 & 3 & 2.7 & $<0.05$ \\
\hline Warfarin & 15 & 6.9 & 15 & 13.3 & NS \\
NOAC & 5 & 2.1 & 1 & 1.3 & NS
\end{tabular}

UC, usual care; CR, cardiovascular rehabilitation; ACE-I, angiotensin-converting-enzyme inhibitor; ARB, angiotensin II receptor blockers; BB, beta-blocker; NOAC, nonvitamin K antagonist oral anticoagulants.

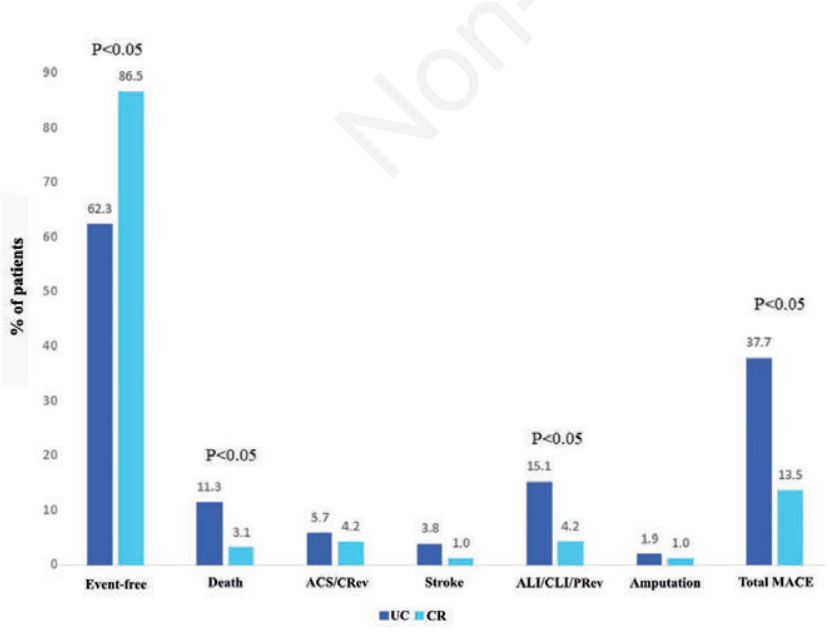

Figure 2. Events during 2-year follow-up in LEPAD patients not referred (UC) and referred (CR) to cardiovascular rehabilitation. UC, usual care; CR, cardiac rehabilitation; ACS, acute coronary syndrome; CRev, coronary revascularization; ALI, acute limb ischemia; CLI, chronic limb ischemia; PRev, peripheral revascularization; MACE, major adverse cardiovascular events. and/or SET in LEPAD patients. Unfortunately, global surveys [17] or national audits [18-20] did not include details of LEPAD as a referral indication to CR per se, being this condition often linked to "other non-coronary CVD" or not considered at all. Small observational studies or questionnaires have demonstrated that referral and participation rates of eligible LEPAD patients is extremely low. During a cross-sectional study, a referral for SET was directly initiated by Dutch general practitioners only in $10 \%$ of new LEPAD patients with IC [21]. Even though reporting of SET trials is generally poor with regard to the numbers of subjects screened and reasons for exclusion to CR, a review performed in 2016 [22] estimated a $24 \%$ uptake rate in the field of IC. To our best knowledge, no exhaustive data are available on LEPAD patients referred to comprehensive $\mathrm{CR}$ after peripheral revascularization.

Unlike low physician commitment, limited resources availability seems to be one of the most important reason for CR underutilization. Structured CR programmes are often poorly dedicated to LEPAD, inadequately linked to the vascular surgery setting, and not everywhere reimbursed, all these factors contributing to unsatisfactory participation rates. A survey carried out by the Vascular Society of Great Britain and Ireland in the year 2009, as for instance, revealed that only $24 \%$ of UK resident surgeons had access to SET for LEPAD patients [23], being presumably this estimate even less when considering a multimodal CR intervention instead of exercise only. Then, when specifically referred for their condition, LEPAD patients constitute a minority of all patients engaged to CR, with a prevalence varying from less than $1 \%$ to $7 \%[12,24]$.

Overall, the current study attested the positive attitude by vascular surgeons towards CR as a treatment option, when adequately offered and incentivized. The referral rate of LEPAD patients we found was superimposable to other cardiac conditions, and confirmed our hypothesis that the global demand for CR by vascular surgery units may be similar to that manifested by cardiac surgery units or acute cardiac wards. Nevertheless, while in the cardiology setting the main need is after surgical or endovascular procedures, vascular surgeons seem to give priority to medically managed patients: recent data from $>500$ US hospitals contributing to the Premier Registry - representing approximately $20 \%$ of inpatient US hospitalizations - reported patient utilization of CR of $43 \%$, $27 \%, 16 \%$, and $11 \%$ after cardiac surgery, percutaneous coronary intervention, medically managed myocardial infarction, and heart failure respectively [25], while in the present survey the utilization of CR was highest in those without invasive therapy (39\%). This may arise from misconception that revascularized patients are not likely to benefit from rehabilitation: structured and intensive CR, on the contrary, may be useful after surgical or endovascular intervention, due to its efficacy in promoting clinical stabilization and better cardiovascular prognosis, in addition to treatment of functional impairment. Peripheral revascularization, rather than an exclusion criterion, is in fact an additional strong indication for participation in a comprehensive CR programme. However, additional benefits derived from the combination of revascularization followed by SET may be no longer present after 12 months [26] and probably, as for other major cardiac conditions [27], there is need for prolonged or recall interventions.

Among potential intervention to improve the delivery of rehabilitation in LEPAD patients, considering SET alone as a surrogate of multimodal CR may not be the best policy, as methods and goals of $\mathrm{CR}$ are wider and include smoking cessation advice, lifestyle counselling, and proper medications up-titration also. Moreover, even when considering both SET and CR together for cardiac conditions, they failed to reach even half of the potentially eligible population [25]. Consequently, attention should be paid to consider CR for 
appropriate LEPAD patients, with a "modern" decisional driver given not just by the evaluation of functional impairment, but also by global cardiovascular risk estimate. In this perspective, our embryonic evidence attesting a better achievement of secondary prevention targets and reduced mortality after having completed a CR programme may support this strategy. In the next future, novel community-based, home-based, and "hybrid" models implementing mhealth, e-health, and telemedicine, will probably help to increase access to CR for LEPAD patients who would otherwise not attend.

Several study limitations deserve to be mentioned. First, the building of the interorganizational network of CR and vascular surgery facilities was somewhat "artificial", thus not completely reflecting the spontaneous attitude of both specialties towards the link between LEPAD and rehabilitation. On the other hand, this permitted to take a snapshot under the unusual condition of attenuate system's level barriers to CR, because of better coordination of transfer of care and cost coverage by the health system. Then, the absence of randomization between groups and the low rate of patients who completed follow-up ( $45 \%$ of those observed at baseline) impose caution in interpreting different outcome results, especially for treatment targets and prognosis, and do not constitute a definite evidence regarding the efficacy of CR in reducing major cardiovascular events in referred LEPAD patients.

In conclusion, our data confirm that CR represent a "should take it and not leave it" intervention [28] also in the field of LEPAD [29], and that this intervention is feasible when healthcare professionals do efforts in service coordination. Nowadays, the great challenge is to systematically ensure this care model at least to those patients at highest cardiovascular risk - particularly after revascularization and not only in presence of chronic intermittent claudication.

\section{References}

1. Piepoli MF, Corrà U, Benzer W, et al. Secondary prevention through cardiac rehabilitation: from knowledge to implementation. A position paper from the Cardiac Rehabilitation Section of the European Association of Cardiovascular Prevention and Rehabilitation. Eur J Cardiovasc Prev Rehab 2010;17:1-17.

2. Piepoli MF, Corrà U, Adamopoulos $\mathrm{S}$, et al. Secondary prevention in the clinical management of patients with cardiovascular diseases. Core components, standards and outcome measures for referral and delivery: a policy statement from the cardiac rehabilitation section of the European Association for Cardiovascular Prevention \& Rehabilitation. Endorsed by the Committee for Practice Guidelines of the European Society of Cardiology. Eur J Prev Cardiol 2014;21:664-81.

3. Gardner AW, Poehlman ET. Exercise rehabilitation programs for the treatment of claudication pain: a meta-analysis. JAMA 1995;274:975-80.

4. Lane R, Ellis B, Watson L, Leng GC. Exercise for intermittent claudication. Cochrane Database Syst Rev 2014:CD000990. Doi:10.1002/14651858.CD000990.pub3

5. Aboyans V, Ricco JB, Bartelink MEL, et al. 2017 ESC Guidelines on the Diagnosis and Treatment of Peripheral Arterial Diseases, in collaboration with the European Society for Vascular Surgery (ESVS): Document covering atherosclerotic disease of extracranial carotid and vertebral, mesenteric, renal, upper and lower extremity arteries. Endorsed by: the European Stroke Organization (ESO) The Task Force for the Diagnosis and Treatment of Peripheral Arterial Diseases of the European
Society of Cardiology (ESC) and of the European Society for Vascular Surgery (ESVS). Eur Heart J 2018;1;39:763-816.

6. Hiatt NL, Dormandy WR, Nehler JA, et al. Inter-society consensus for the management of peripheral arterial disease (TASC II). J Vasc Surg 2007;45:S5-67.

7. McDermott MM, Ferrucci L, Liu K, et al. Leg symptom categories and rates of mobility decline in peripheral arterial disease. J Am Geriatr Soc 2010;58:1256-62.

8. Ambrosetti M. Advances in exercise rehabilitation for patients with Lower Extremity Peripheral Artery Disease. Monaldi Arch Chest Dis 2016;86:752. doi:10.4081/monaldi.2016.752.

9. Aherne T, McHugh S, Kheirelseid EA, et al. Comparing supervised exercise therapy to invasive measures in the management of symptomatic peripheral arterial disease. Surg Res Pract 2015;2015:960402.

10. Menêses AL, Ritti-Dias RM, Parmenter B, et al. Combined lower limb revascularisation and supervised exercise training for patients with peripheral arterial disease: A systematic review of randomised controlled trials. Sports Med 2017;47:987-1002. doi: 10.1007/s40279-016-0635-5.

11. Resurrección DM, Moreno-Peral P, Gómez-Herranz M, et al. Factors associated with non-participation in and dropout from cardiac rehabilitation programmes: a systematic review of prospective cohort studies. Eur J Cardiovasc Nurs 2019;18:3847. doi: $10.1177 / 1474515118783157$.

12. Ambrosetti M, Temporelli PL, Faggiano P, et al. Lower extremities peripheral arterial disease among patients admitted to cardiac rehabilitation: The THINKPAD registry. Int $\mathrm{J}$ Cardiol 2014;171:192-8.

13. Pedretti RFE, Fattirolli F, Griffo R, et al. Cardiac Prevention and Rehabilitation "3.0": From acute to chronic phase. Position Paper of the ltalian Association for Cardiovascular Prevention and Rehabilitation (GICR-IACPR). Monaldi Arch Chest Dis 2018;26;88:1004. doi: 10.4081/monaldi.2018.1004.

14. Balady GJ, Ades PA, Bittner VA, et al. Referral, enrollment, and delivery of cardiac rehabilitation/secondary prevention programs at clinical centers and beyond: a presidential advisory from the American Heart Association. Circulation 2011;124:2951-60.

15. Suaya JA, Shepard DS, Normand ST, et al. Use of cardiac rehabilitation by Medicare beneficiaries after myocardial infarction or coronary bypass surgery. Circulation 2007;116:1653-62.

16. Catapano AL, Graham I, De Backer G, et al. 2016 ESC/EAS Guidelines for the Management of Dyslipidaemias. Eur Heart J 2016;37:2999-3058. doi: 10.1093/eurheartj/ehw272.

17. Lima de Melo Ghisi G, Pesah E, Turk-Adawi K, et al. Cardiac Rehabilitation Models around the Globe. J Clin Med 2018;7. pii: E260. doi: 10.3390/jcm7090260.

18. Sumner J, Grace SL, Doherty P. Predictors of cardiac rehabilitation utilization in England: Results from the national audit. J Am Heart Assoc 2016;5. pii: e003903.

19. Grace SL, Oh PI, Marzolini S, et al. Observing temporal trends in cardiac rehabilitation from 1996 to 2010 in Ontario: characteristics of referred patients, programme participation and mortality rates. BMJ Open 2015;5:e009523. doi: 10.1136/bmjopen2015-009523.

20. Grace SL, Parsons TL, Heise K, Bacon SL. The Canadian Cardiac Rehabilitation Registry: Inaugural report on the status of cardiac rehabilitation in Canada. Rehabil Res Pract 2015;2015:278979. doi: 10.1155/2015/278979.

21. Hageman D, Pesser N, Gommans LNM, et al. Limited adherence to peripheral arterial disease guidelines and suboptimal ankle brachial index reliability in Dutch primary care. Eur J Vasc 
Endovasc Surg 2018;55:867-73. doi: 10.1016/j.ejvs.2018. 02.011.

22. Harwood AE, Smith GE, Cayton T, et al. A Systematic review of the uptake and adherence rates to supervised exercise programs in patients with intermittent claudication. Ann Vasc Surg 2016;34:280-9. doi: 10.1016/j.avsg.2016.02.009.

23. Shalhoub J, Hamish M, Davies AH. Supervised exercise for intermittent claudication - an under-utilised tool. Ann R Coll Surg Engl 2009;91:473-6. doi: 10.1308/003588409X432149.

24. Jeger RV, Rickenbacher P, Pfisterer ME, Hoffmann A. Outpatient rehabilitation in patients with coronary artery and peripheral arterial occlusive disease. Arch Phys Med Rehabil 2008;89:618-21. doi: 10.1016/j.apmr.2007.09.040.

25. Pack QR, Priya A, Lagu T, et al. Cardiac rehabilitation utilization during an acute cardiac hospitalization: a national sample. J Cardiopulm Rehabil Prev 2019;39:19-26. doi: 10.1097/HCR. 0000000000000374.

26. Klaphake S, Buettner S, Ultee $\mathrm{KH}$, et al. Combination of endovascular revascularization and supervised exercise therapy for intermittent claudication: a systematic review and metaanalysis. J Cardiovasc Surg 2018;59:150-7.

27. Belardinelli R, Georgiou D, Cianci G, Purcaro A. 10-year exercise training in chronic heart failure: a randomized controlled trial. J Am Coll Cardiol 2012;60:1521-8. doi: 10.1016/j.jacc. 2012.06.036.

28. Taylor R, Dalal H, Davies R, et al. Cardiac rehabilitation in heart failure with reduced ejection fraction: A "should take it and not leave it" intervention. Am Heart J 2017;192:e1-e2. doi: 10.1016/j.ahj.2017.07.007.

29. Gerhard-Herman MD, Gornik HL, Barrett C, et al. 2016 AHA/ACC guideline on the management of patients with lower extremity peripheral artery disease: a report of the American College of Cardiology/American Heart Association Task Force on Clinical Practice Guidelines. Circulation 2017;135:e726-79. doi: 10.1161/CIR. 0000000000000471 . 